\title{
A lucratividade dos bancos norte-americanos após a crise de 2007/2008
}

\author{
U.S. banks profitability after the $2007 / 2008$ crisis
}

MARCO BULHÕES CECILIO*

\begin{abstract}
RESUMO: Este trabalho tem como objetivo avaliar como se comportou a rentabilidade dos grandes bancos Norte-americanos após a crise de 2007/2008, além de buscar explicações preliminares que ajudem a explicar o comportamento encontrado. Para isso, avalia os dados históricos de 1932 até 2015. Os resultados mostram que a fatia dos lucros totais da economia Norte-americana capturada pelo setor financeiro reduziu-se em relação ao auge dos anos 2000, mas ainda se encontra em patamar superior ao do período pós-Guerra. Os indícios apontam para a diminuição da alavancagem por pressão regulatória como principal causador da redução.

PALAVRAS-CHAVE: Setor financeiro; lucratividade; crise de 2007/2008; bancos; sell side.
\end{abstract}

ABSTRACT: This paper aims to evaluate the profitability of the major North-american banks after the crisis of 2007-2008, as well as to seek preliminary explanations to the results found. To do so, it assesses the historical data from 1932 until 2015. The results show that the share of total profits in the North-american economy captured by the financial sector has reduced compared to the peak of the last decade but is still at a higher level than the postwar baseline. The evidence points to the decrease of leverage by regulatory pressure as the main cause of the reduction.

KEYWORDS: Financial sector; profitability; 2007-2008 crisis; banks; sell side.

JEL Classification: E01; G21; N22.

\section{INTRODUÇÃO}

Em artigo publicado pela revista New Yorker em dezembro de 2015, Gary Sernovitz (2015), diretor de um fundo de private equity focado em óleo e gás, con-

\footnotetext{
* Doutorando em Economia Política Internacional no Instituto de Economia da Universidade Federal do Rio de Janeiro, RJ - Brasil. E-mail: marco.cecilio@gmail.com.
} 
duz uma breve análise das propostas de reforma financeira que à época eram defendidas pelas duas principais pré-candidaturas democratas nos EUA: Bernie Sanders e Hillary Clinton. A principal bandeira de Sanders, que declaradamente se colocava como um inimigo de Wall Street, era a divisão dos bancos grandes demais para quebrar (too big to fail) em instituições menores, numa espécie de restituição e aprofundamento do Glass-Steagall Act promulgado após a crise de 1929 e que determinava a separação dos bancos comerciais dos bancos de investimento. Já Hillary Clinton, amplamente criticada pela campanha de Sanders por suas conexões com Wall Street - quatro dos cinco maiores doadores em toda sua carreira política são bancos Norte-americanos ${ }^{1}$ - não excluía a possibilidade de se dividir os grandes bancos, mas posiciona-se claramente a respeito dos limites desta ação: numa era de crescente relevância do shadow banking system, concentrar os esforços na divisão dos bancos seria insuficiente (Clinton, 2015).

Sernovitz em momento algum se alinha de forma clara com a necessidade de reforma no sistema financeiro, mas entre as duas posições não tem dúvidas em afirmar que o posicionamento de Hillary Clinton traduziria uma compreensão mais completa do que se passa hoje em Wall Street. Na essência desta distinção, estaria o que ele chama de uma das histórias centrais do mercado financeiro desde a década de 1990: "a estagnação do sell side e a ascensão do buy side, em função de mudanças na tecnologia, regulação e novas oportunidades de lucro".

A divisão do mundo financeiro entre sell side e buy side é uma das formas clássicas de segmentar o setor: no sell side estão as instituições que vendem serviços financeiros, tais como consultoria em fusões e aquisições, criação e emissão de títulos e derivativos entre outros. Os bancos, sejam comerciais ou de investimento encontram-se aqui. Do lado oposto, no buy side, estão as instituições que efetivamente gerenciam ativos sob diversas estruturas: hedge funds, private equitys, venture capital e fundos mútuos, entre outros.

O argumento de Sernovitz é que os bancos, o sell side, não são mais a máquina de fazer dinheiro que um dia foram. Como exemplo, cita que o lucro dos seis maiores bancos norte-americanos em 2014 foi $17 \%$ menor do que os lucros de 2006 e se estes números fossem ajustados para considerar algumas das fusões do período, os lucros seriam $37 \%$ menores. Por outro lado, a nova máquina de dinheiro - e também de relevância e influência política - estaria com as novas e crescentes instituições do buy side. Tal argumento pode ser contestado, mas crescem as vozes que apontam nesta direção. ${ }^{2}$ Desta forma, num mundo em que o sell side estaria perdendo força, ou seja, em que crescem as instituições do buy side com grande capacidade de mobilizar recursos sem necessitar dos grandes bancos, a mira dos reguladores deveria mudar. Do típico - e fácil - alvo político dos bancos

\footnotetext{
${ }^{1}$ Dados compilados por OpenSecrets, Center for Responsive Politics. Disponível em https://www. opensecrets.org/politicians/contrib.php?cid=N00000019\&cycle=Career.

${ }^{2}$ Ver, por exemplo, Marsh e Natarajan (2016).
} 
grandes demais para quebrar, o desafio passaria a ser a supervisão de um leque muito mais amplo e complexo de fundos cada vez mais relevantes que os bancos.

Em que pese o caráter de discurso político destas posições, suas reverberações para a análise do sistema financeiro na academia são relevantes. A ampla literatura a respeito da financeirização da economia global ${ }^{3}$ de forma alguma ignora a crescente relevância do shadow banking system ${ }^{4}$ mas tampouco aponta para uma eventual redução na capacidade de geração de lucros dos bancos. Identificar se, e de que forma, está ocorrendo esta queda na rentabilidade dos grandes bancos é altamente relevante para uma compreensão detalhada dos movimentos de acumulação de riquezas de forma acelerada no mundo atual. Além disso, são raras na academia as análises que conseguem transitar do nível macro, nos quais se pode perceber a crescente financeirização da economia, para um nível mais micro que identifique as mudanças na composição do setor financeiro e o impacto sistêmico deste movimento.

Assim, partindo de uma provocação que esteve viva na campanha eleitoral norte-americana, mas com impacto na discussão acadêmica sobre a dinâmica de acumulação de riquezas no setor financeiro, este trabalho se propõe a analisar indícios desta redução na relevância do sell side em relação ao buy side. Tal investigação, no entanto, possui um escopo mais amplo do que é possível neste trabalho, até porque a opacidade de dados a respeito do buy side traz dificuldades consideráveis para a pesquisa. Assim, mais particularmente, este trabalho avaliará a hipótese de que os grandes bancos americanos reduziram sua capacidade de gerar lucros após a crise de 2008 .

Cabe aqui ressalvar que, embora não seja tratado neste trabalho, existem outras análises possíveis que podem oferecer outras visões sobre a relevância dos grandes bancos americanos. Como exemplo, pode-se especular que mesmo que sua lucratividade tenha caído, os grandes bancos sigam com significativo potencial de desestabilização sistêmica e, assim, mesmo que menos lucrativos, seguiriam no centro do debate político Norte-americano.

Além desta pergunta que trata da lucratividade dos bancos, uma outra questão é necessária para um quadro mais completo da situação: como se comportaram os lucros financeiros como um todo na economia Norte- americana no pós-crise? Tal pergunta é essencial para avaliar se a flutuação da rentabilidade dos bancos refletiu um movimento maior do sistema financeiro ou se refletiu uma dinâmica específica destas instituições do sell side.

Um aspecto que oferece relevância a esta pesquisa é seu arco temporal. A opção aqui é estender os dados ao menos até 2014 e, quando possível, 2015. A produção acadêmica que se debruça sobre a relevância do setor financeiro e sua lucratividade com dados dos últimos anos ainda é rara: a maior parte dela tem se concentrado, no máximo, a investigar os desdobramentos do imediato pós-crise, com foco nos primeiros anos de recuperação após o choque de 2008. Ao expandir

\footnotetext{
${ }^{3}$ Epstein (2015) e Nölke, Heires e Billing (2013) oferecem bons panoramas desta produção.

${ }^{4}$ Ver, por exemplo, Cintra e Cagnin (2007) e Adrian e Ashcraft (2010).
} 
os dados até 2015, esta pesquisa ajuda a oferecer um quadro mais claro de um cenário em constante movimento.

Para facilitar a exposição ao leitor, este trabalho está organizado em três seções. $\mathrm{Na}$ primeira, serão exploradas as variações como um todo na lucratividade do setor financeiro Norte- americano. Na segunda seção, a questão da lucratividade dos bancos, e assim da relação sell side $\mathrm{x}$ buy side, será trabalhada. Na terceira, a variação da rentabilidade é contrastada com parte da literatura sobre o tema e, ao final, uma conclusão com os principais achados e uma nova agenda de pesquisa é apresentada.

\section{LUCROS DO SETOR FINANCEIRO NO PÓS-CRISE}

Como relembra Helleiner (2010), após a crise de 2007-2008 diversos analistas e políticos flertaram com a ideia de que um "novo Bretton Woods” estaria por emergir dos escombros da pior crise global desde 1929. Após décadas de desregulamentação que permitiram uma notável ascensão do setor financeiro, este seria enquadrado dentro de um novo arranjo monetário global mais estável e com algum freio às finanças. No entanto, o próprio Helleiner em seu artigo de 2010 já identificava que tal movimento constitutivo de um novo sistema dificilmente ocorreria. Embora fosse possível que estivéssemos vivendo uma crise de legitimidade da ordem internacional neoliberal das últimas três décadas, as condições para a construção de um novo arranjo ainda não estariam dadas.

É fácil compreender estas visões quando se considera o contexto daquele momento: em 2008, no auge da crise, os lucros financeiros haviam despencado e não chegavam a um quarto do que haviam sido dois anos antes, no pico da fase de exuberância. Como comparação, na série histórica que computa os lucros totais na economia Norte- americana iniciada em 1929, a maior queda dos lucros financeiros havia ocorrido na crise de 1980 , quando a massa de lucros caiu $16 \%$ em relação a 1979 , uma perda tímida em comparação ao mergulho de $68 \%$ em $2008 .{ }^{5}$ Foi neste contexto de um recuo dramático da rentabilidade das finanças que as previsões de um novo momento Bretton Woods foram levantadas.

No entanto, já em 2009 o setor havia se recuperado de forma vistosa e em 2010 a massa de lucros do setor financeiro em números absolutos atingiu o segundo maior nível da história até então. Após o colapso de 2008, a rentabilidade financeira voltava aos níveis sem par dos anos pré-crise. Parecia evidente que retornáramos ao business as usual das últimas duas décadas.

No entanto, para confirmar tal observação é necessário alongar o horizonte de análise até o momento atual. Porém, antes de tal avaliação é válido destacar que na ampla literatura que vem sendo desenvolvida a respeito da financeirização da economia global, o uso dos dados da lucratividade do setor financeiro é contumaz.

\footnotetext{
${ }^{5}$ Tal número é ainda uma pálida versão da realidade, já que os lucros de 2007 já apresentavam queda de $27 \%$ em relação a 2006 . A queda total em dois anos foi de $77 \%$.
} 
Como exemplo, pode-se apontar que a recorrentemente citada análise de Krippner (2011) sobre a financeirização tem como ponto de partida um gráfico muito similar ao que se apresentará na sequência, apontando a crescente participação dos lucros financeiros na massa total dos lucros corporativos nos EUA, em contraste com a queda dos lucros industriais. ${ }^{6}$ Assim, repete-se aqui um ângulo de observação já consagrado na análise das mudanças estruturais mais recentes da economia.

E o que o Gráfico $1^{7}$ nos mostra, de forma inusitada para aqueles que apostavam no retorno do business as usual, é que após a recuperação imediata dos lucros financeiros logo após a crise, sua participação nos lucros totais da economia decaiu de forma razoavelmente consistente nos últimos cinco anos. Desde 2013 a indústria voltou a ter uma participação maior nos lucros do que as finanças, o que, com a exceção dos anos da crise, não ocorria desde 2000. Mais surpreendente, a participação do setor financeiro nos lucros em 2015 foi de 17,6\%, a menor desde 1988 - claro, novamente com exceção de 2008 - e está muito longe da média de $30 \%$ dos lucros entre 2001 e 2007.

Gráfico 1: Participação das Finanças e da Indústria nos lucros totais da economia americana

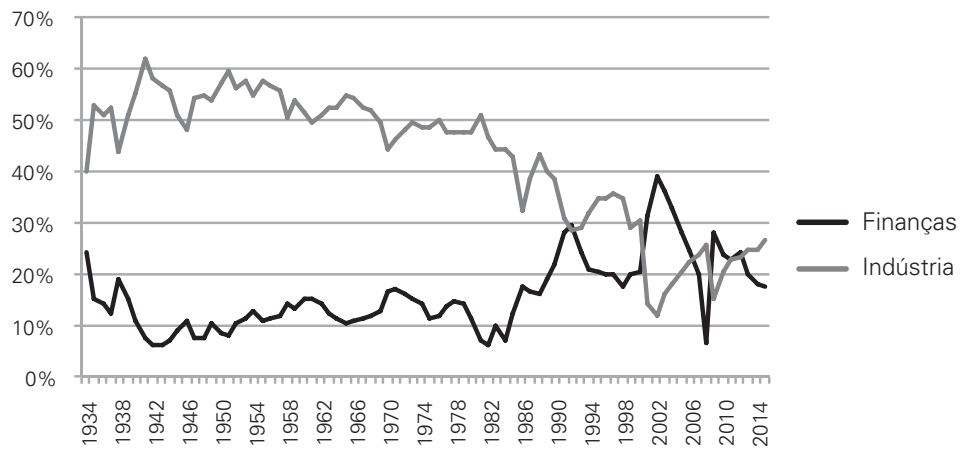

Fonte: Tabelas 6.16 das National Income and Product Accounts disponibilizadas pelo US Bureau of Economic Analysis.

\footnotetext{
${ }^{6}$ Krippner (2011) destaca que a análise da rentabilidade é essencial para evidenciar que a mudança estrutural observada na economia Norte-americana desde a década de 1980 não é simplesmente uma migração de uma economia industrial para uma economia pós-industrial, mas sim a ascensão do setor financeiro. Uma análise que se limita a observar as mudanças na oferta de empregos e na participação do PIB, sem avaliar os lucros, apontaria apenas da direção do pós-industrialismo, não sendo capaz de perceber a escalada das finanças. Uma ressalva importante é que o gráfico de Krippner destaca ainda a lucratividade dos outros serviços além das finanças, pois mostrar o descasamento destes com os lucros financeiros é relevante em seu argumento.

${ }^{7}$ Os dados da tabela NIPA para o setor financeiro englobam a totalidade de agentes do setor, como bancos comerciais e de investimento, bancos universais, seguradoras e até mesmo os Federal Reserve Banks. Os dados não consideram o lucro de empresas financeiras obtidos no exterior. Os dados de 2015 são uma estimativa baseada nos resultados apresentados até o terceiro trimestre do ano. Para esta análise, os dados de rentabilidade dos 12 Federal Reserve Banks dos EUA não foram considerados. Os lucros destes bancos desde a crise de 2008 tem girado em torno de $5 \%$ dos lucros totais dos EUA, pouco acima da média histórica das últimas três décadas.
} 
Sintomaticamente, há exemplos de forte carga simbólica desta reversão: a General Eletric, uma das mais representativas empresas industriais norte-americanas, tornara-se nas últimas décadas um híbrido de empresa-banco. Por meio de sua divisão GE Capital, chegou a ter metade de seus lucros derivados de operações financeiras e era recorrentemente citada como um exemplo da financeirização da economia (Krippner, 2011). A queda da rentabilidade acompanhada do crescente peso regulatório sobre a empresa ${ }^{8}$ fizeram com que a General Electric em 2015 decidisse vender a maior parte da sua divisão financeira, voltando a concentrar seus negócios na produção industrial, de onde espera tirar 90\% de seus lucros em 2018 (Smith, 2015).

Embora estes dados apontem para uma queda na relevância do setor financeiro, diversas ressalvas são necessárias. A primeira, e talvez mais relevante delas, é que mesmo o nível "baixo" de 17,6\% dos lucros totais em 2015 permanece em um patamar claramente superior ao que se pode observar antes da década de 1990. Os números recentes, ao menos até o momento, parecem mais ser um limiar baixo do padrão inaugurado no final dos 1980 do que um retorno ao padrão de lucros reduzidos do pós-Guerra. Um outro modo de evidenciar a continuada capacidade do setor financeiro de gerar lucros é compará-lo à evolução do PIB Norte-americano, como mostrado no gráfico 2. Como se observa, o nível dos lucros em 2014, embora decrescente em relação aos anos do auge da bonança financeira, ainda está bastante acima de qualquer comparativo anterior à 2002 .

\section{Gráfico 2: Lucros financeiros em relação ao PIB}

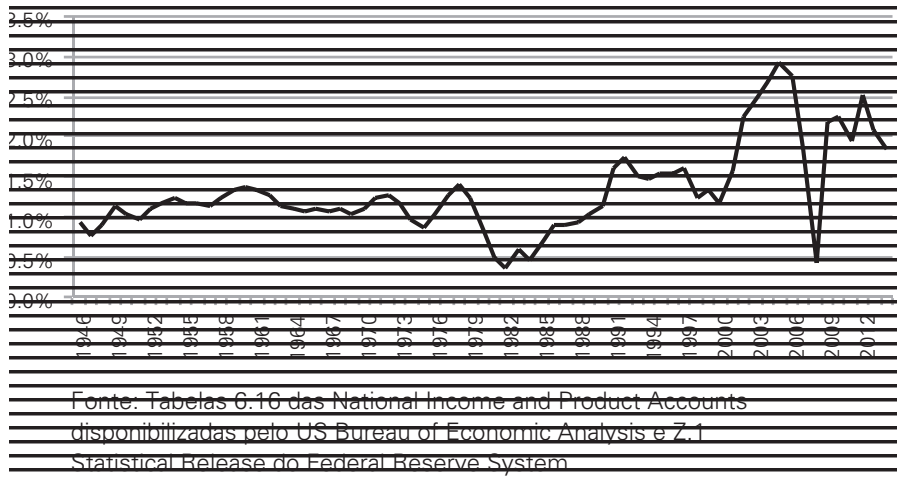

Outra ressalva é que, embora o decréscimo seja razoavelmente consistente nos últimos anos, o intervalo de tempo ainda é curto para se configurar num novo patamar ou até mesmo numa tendência clara. Os resultados finais de 2015, ainda em compilação, e os dados da segunda metade da atual década serão fundamentais para

\footnotetext{
${ }^{8}$ A GE Capital foi designada em 2013 pelo FSOC (Financial Stability Oversight Council) uma instituição financeira sistemicamente importante, o que implicava uma carga regulatória mais pesada para a companhia. Com a venda dos ativos, a mesma perdeu o status em 2016.
} 
esclarecer a natureza do movimento. Por fim, mas extremamente relevante, é que a queda se deu no percentual dos lucros financeiros em relação à massa total de lucros da economia, mas não nos lucros financeiros de forma absoluta. Como se observa no Gráfico 3, houve evolução na massa total dos lucros financeiros entre 2009 e 2015 - um crescimento anual médio de $1,85 \%$. No entanto, os lucros corporativos como um todo cresceram de forma muito mais veloz no mesmo período: um crescimento médio de $10 \%$ ao ano, chegando a mais de $20 \%$ ao ano para o setor industrial.

Gráfico 3: Lucros financeiros: números absolutos (em bilhões de dólares) e participação nos lucros totais
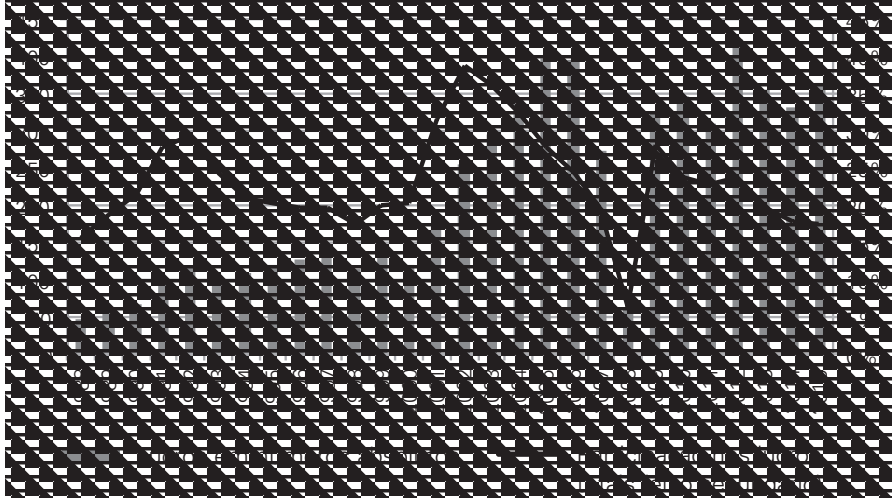

Fonte: Tabelas 6.16 das National Income and Product Accounts disponibilizadas pelo US Bureau of Economic Analysis.

Assim, o que se observou nestes últimos cinco anos foi uma perda da posição relativa da capacidade das finanças em capturar os lucros da economia Norte- americana como um todo, mas não um recuo em termos absolutos de sua capacidade de gerar lucros. Neste sentido, isto abre uma nova agenda de pesquisa muito relevante, mas que está fora do escopo deste trabalho: como explicar a rapidíssima expansão dos lucros corporativos enquanto a economia seguia em expansão muito mais lenta nos EUA.

A este respeito, duas hipóteses têm sido apontadas costumeiramente: a primeira é que a estagnação dos salários, numa recuperação econômica que ocorreu sem retomada do emprego, ofereceu uma margem sem precedentes para a expansão da lucratividade das empresas. A segunda, e que ajudaria a explicar o descolamento entre taxa de crescimento do PIB e das taxas de lucro, aponta que a lucratividade das empresas americanas tem sido ampliada por sua atuação internacional, ao remeter de volta para casa lucros substantivos. Mais ao espírito desta pesquisa, uma terceira variável mereceria análise: como se comportou o lucro financeiro das empresas não financeiras. Na literatura sobre a financeirização da economia global, o crescente componente financeiro dos lucros de empresas não financeiras é uma evidência forte do processo de ascensão das finanças. O já citado caso da GE Capital seria um sinal de uma mudança nesta questão, mas uma investigação mais ampla poderia ser conduzida para melhor compreender esta dinâmica nestes últimos cinco anos. 


\section{A DERROCADA DO SELL-SIDE? OS GRANDES BANCOS E SUA LUCRATIVIDADE NO PÓS-CRISE}

Com uma percepção mais clara da dimensão dos lucros financeiros na economia Norte-americana no pós-crise, crescentes em termos nominais porém em queda como participação no total dos lucros da economia, podemos avançar para a questão mais específica da lucratividade dos bancos. Para isso, é necessário inicialmente se estabelecer quais bancos serão incluídos na análise.

A concentração bancária nos EUA cresceu após a crise de 2008, de forma que os bancos considerados "grandes demais para quebrar" em 2008 tornaram-se ainda maiores nos últimos $\operatorname{anos}^{9}$ e formam atualmente um conjunto de seis grandes instituições apresentadas na Tabela 1. Quando Bernie Sanders citava os grandes bancos, em seu insistente bordão de pré-campanha de que os bancos grandes demais para quebrar são grandes demais para existir, é nestes seis bancos que está mirando, ${ }^{10}$ até porque o sétimo maior banco dos EUA, o U.S. Bancorp, possui apenas cerca da metade dos ativos do menor dos seis bancos, o Morgan Stanley.

Tabela 1: Maiores bancos dos EUA

(Ativos - em milhões de dólares)

\begin{tabular}{|c|c|c|}
\hline Posição & Banco & Ativos totais \\
\hline 1 & JP Morgan Chase & 2.573 .126 \\
\hline 2 & Bank of America & 2.104 .534 \\
\hline 3 & Citigroup & 1.843 .000 \\
\hline 4 & Wells Fargo & 1.687 .155 \\
\hline 5 & Goldman Sachs & 856.240 \\
\hline 6 & Morgan Stanley & 801.510 \\
\hline
\end{tabular}

Fonte: Dados dos relatórios anuais das empresas e de ranking compilado pela SNL Financial, disponível em https://www.snl.com/InteractiveX/Article.aspx?cdid=A-31327166-11318.

A respeito da estrutura destes bancos, algumas observações são importantes. JP Morgan Chase, Bank of America e Citigroup combinam grandes operações como bancos comerciais com grandes operações como bancos de investimento. ${ }^{11} \mathrm{O}$ Wells Fargo também, embora sua atuação como banco de investimento seja um tanto reduzida em relação aos três já citados. Goldman Sachs e Morgan Stanley concen-

\footnotetext{
${ }^{9}$ Ainda assim, os níveis de concentração bancária nos EUA seguem menores que os observados na maior parte dos países da OCDE (Council of Economic Advisers, 2017).

${ }^{10}$ Além das maiores seguradoras.

${ }^{11}$ Como referência, em julho de 2013 mais de $60 \%$ dos lucros do Citigroup vinham do braço de investimento, assim como mais de $40 \%$ dos lucros do JP Morgan.
} 
tram suas operações como bancos de investimento, sem braços significativos de operação como bancos comerciais, embora ambos tenham alterado seu status junto ao FED como “bank holding companies" em 2008, sendo assim regulados como bancos universais.

Assim, são estes seis maiores bancos, tratados de forma agrupada combinando suas operações como bancos comerciais e bancos de investimento, que serão considerados em nossa análise. Antes de fazê-la, no entanto, uma breve consideração a respeito da concentração dos ativos e o papel das fusões e aquisições é importante. A concentração bancária nos EUA é costumeiramente analisada usando como indicador o percentual dos ativos bancários totais que se concentra nos cinco maiores bancos do país. Tal número foi crescente durante a década passada e embora tenha se estabilizado após 2010, expandiu-se no imediato pós-2008, saltando de 42\% em 2006, no auge do boom, para 47\% em 2013.

Este crescimento da concentração bancária se deveu em parte às aquisições feitas durante a crise, muitas delas incentivadas pelo próprio governo Norte-americano que tentava evitar um colapso completo do setor. Das aquisições que envolveram os seis maiores bancos que são foco deste trabalho, algumas merecem ser destacadas pelo significativo porte das instituições adquiridas. Todas estas aquisições foram realizadas em 2008:

- Compra da Countrywide Financial e do Merril Lynch pelo Bank of America;

- Compra do Bear Stearns e do Washington Mutual pelo JP Morgan;

- Compra do Wachovia pelo Wells Fargo.

Tais aquisições foram destacadas para que na avaliação que faremos a seguir a respeito da lucratividade dos seis maiores bancos, os lucros das instituições adquiridas possam ser considerados, de forma a criar condições simétricas na análise pré e pós-crise.

Assim, para a análise foram levantados os principais indicadores financeiros dos grandes bancos no período de 2001 a 2014 por meio de seus balanços publicados anualmente. ${ }^{12}$ Os resultados estão expostos no Gráfico 5 , que apresenta nas colunas a evolução do percentual dos lucros totais da economia Norte-americana capturado pelos seis maiores bancos, sendo que para os anos que antecedem as aquisições de 2008 agregou-se o resultado das instituições adquiridas. Já a linha representada no eixo secundário apresenta o retorno sobre o capital dos seis bancos. Ambas informações evidenciam o estabelecimento de um novo patamar de rentabilidade mais baixo após a crise: enquanto no período 2001-2006 os lucros dos

\footnotetext{
${ }^{12} \mathrm{Na}$ análise serão comparados os dados de lucros publicados pelos bancos com os dados agregados de lucratividade na economia Norte-americana publicados pelo BEA, Bureau of Economic Analysis, agência ligada ao Departamento de Comércio dos EUA. Os padrões de contabilidade utilizados na apuração dos dois lucros não são os mesmos, mas ainda assim permitem a identificação de algumas macro tendências. Recomenda-se ver a comparação apresentada por Hodge (2011) entre as metodologias para apuração de lucros do BEA e da S\&P 500 Profits para uma avaliação mais completa das diferenças e semelhanças na apuração destes resultados e sua problemática.
} 
seis bancos, considerando as empresas que seriam por eles adquiridos em 2008, representaram em média 6,84\% dos lucros totais dos EUA, no período 2009-2014 o percentual capturado foi de $3,94 \%$, uma redução de mais de $40 \%$. Já o retorno sobre o capital caiu de 14,75\% entre 2001 e 2006 para 6,59\% entre 2009 e 2014 .

Tais números deixam claro que os bancos não retomaram nestes últimos seis anos o excepcional nível de rentabilidade alcançado na primeira metade da última década, o que reforçaria a hipótese levantada no início do trabalho de que os bancos perderam parte da capacidade de gerar lucros nesta nova conjuntura.

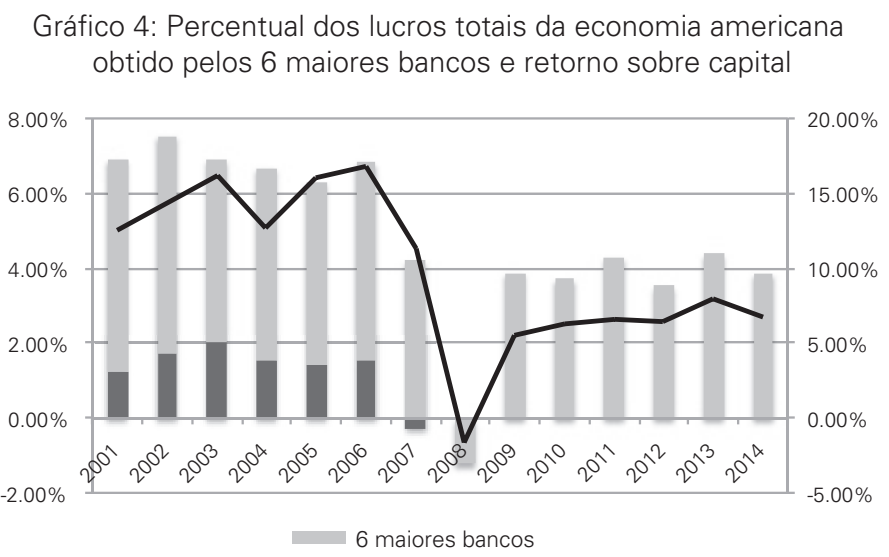

Fonte: Balanços anuais dos bancos, das empresas adquiridas e Tabelas 6.16 das National Income and Product Accounts disponibilizadas pelo US Bureau of Economic Analysis.

Uma primeira hipótese para esta redução seria o incomum quadro de um período estendido com taxas de juros próximas de zero nos EUA. Taxas de juros mais baixas estão associadas em geral a menores spreads, o que implicaria uma redução da rentabilidade bancária. É provável que parte da queda da rentabilidade esteja ligado a este fato, porém seu grau de explicação é limitado. Estudo de Di Lucido, Kovner e Zeller (2017), economistas do FED, aponta que os spreads entre 2009 e 2011 seguiam maiores ou ao menos similares aos de $2006^{13}$ e mesmo assim a redução na rentabilidade dos bancos neste período é significativa, o que contraria a tese de redução dos lucros principalmente em função da redução da taxa de juros. Assim, outras variáveis foram importantes neste processo de perda de lucratividade.

Cabe ainda avaliar se esta redução da lucratividade dos seis grandes bancos usados nesta análise, combinando suas operações como bancos comerciais e de investimento, acompanhou a redução mais ampla da massa total de lucros financeiros para se avaliar se há, de fato, uma migração de rentabilidade do sell side

\footnotetext{
${ }^{13}$ Como os custos de captação dos bancos também caem com a redução das taxas de juros, por um breve período a redução atua de forma favorável nos spreads para os bancos. Ver Di Lucido, Kovner e Zeller (2017) e Borio, Gambacorta e Hofmann (2015).
} 
para o buy side ou se a redução da rentabilidade dos bancos apenas acompanhou a redução da lucratividade do setor financeiro como um todo.

Tal análise, destacada no Gráfico 5, apresenta, no entanto, resultados inconclusivos. Para o período 2009-2012, a resposta parece ser afirmativa: os bancos de fato capturaram uma fatia significativamente menor dos lucros financeiros. A média do período é de 15,7\% dos lucros, enquanto no período 2001-2006 a média foi de 21,9\%, uma redução de mais de um quarto. Mesmo em 2011, quando a fatia dos grandes bancos atingiu 18,8\%, ainda esteve abaixo do pior ano do período 201-2006. E se os maiores bancos lucraram menos, a hipótese de que as instituições do buy side aumentaram sua lucratividade torna-se bastante razoável, embora novos dados precisassem ser buscados para confirmar a afirmação.

Gráfico 5: Percentual dos lucros financeiros totais obtido pelos 6 maiores bancos

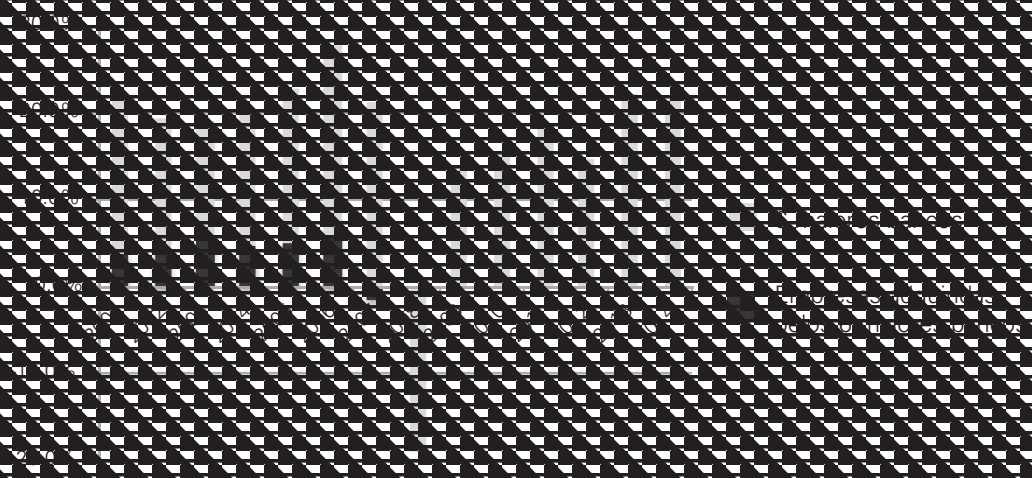

Fonte: Balanços anuais dos bancos, das empresas adquiridas e Tabelas 6.16 das National Income and Product Accounts disponibilizadas pelo US Bureau of Economic Analysis.

Entretanto, os dados mais recentes, de 2013 e 2014, contam outra história: houve significativa recuperação relativa dos lucros dos grandes bancos, abocanhando cerca de $22 \%$, uma média similar ao do período 2001-2006. Configurada esta retomada do patamar anterior, a hipótese de que o buy side teria ganhado espaço na sua disputa com o sell side se mostraria falsa. ${ }^{14}$

Uma primeira linha de pesquisa para compreender esta conjuntura de 2013 e 2014 é apontada a partir do Gráfico 6, o qual mostra que especialmente em 2013 um evento raro aconteceu: enquanto os lucros financeiros como um todo caíram, praticamente todos os grandes bancos aumentaram sua rentabilidade, sendo que a norma observável em praticamente todos os outros anos do período de análise é que os lucros dos bancos sigam a mesma direção do setor financeiro como um todo.

\footnotetext{
${ }^{14}$ É interessante notar que é justo nos anos mais recentes, quando os spreads bancários se comprimiram ainda mais, que os bancos estudados mostram recuperação de sua rentabilidade em comparação com os outros atores financeiros, mostrando, em princípio, ausência de correlação entre sua rentabilidade relativa ao restante do setor e os spreads bancários.
} 
Gráfico 6: Evolução dos lucros - 6 maiores bancos e lucros financeiros como um todo (em bilhões de dólares / setor financeiro no eixo secundário)

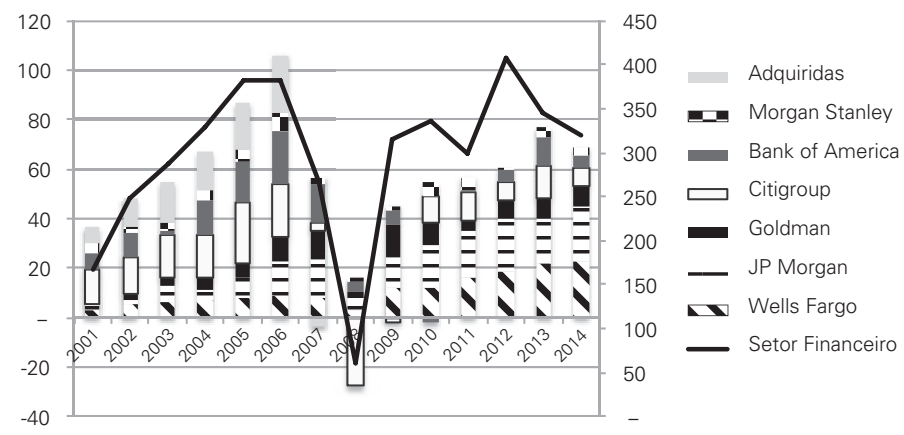

Fonte: Balanços anuais dos bancos, das empresas adquiridas e Tabelas 6.16 das National Income and Product Accounts disponibilizadas pelo US Bureau of Economic Analysis.

Para desvendar estes resultados específicos de 2013 e 2014, seria necessário contrastar o resultado geral do setor financeiro com uma criteriosa análise dos demonstrativos de resultados e do balanço patrimonial destes seis bancos para estes anos, uma tarefa além do alcance deste trabalho e, nas palavras de Crotty (2007), nada invejável. ${ }^{15}$

Para obtermos um quadro mais completo a respeito da lucratividade destes bancos um último comparativo é necessário. Até aqui os lucros dos bancos foram observados em comparação aos lucros totais da economia Norte-americana e aos lucros financeiros totais. Mas como eles se comportaram em relação a outro indicador da economia real, o PIB? É isto que avaliamos no Gráfico 9, a seguir.

Como se pode observar, os lucros dos seis grandes bancos em relação ao PIB vem se recuperando de forma razoavelmente consistente desde 2009 e atingiram em 2014 um patamar similar aos do início da década passada. Assim, se a capacidade de geração de lucros não é a mesma alcançada no auge da década passada, ela já retomou níveis bastante significativos. Uma análise adicional que poderia ser realizada em trabalhos futuros seria ampliar esta análise da relação entre os lucros dos seis bancos e o PIB às décadas de 1980 e 1990, ${ }^{16}$ o que ofereceria um comparativo mais rico do patamar alcançado após a crise.

\footnotetext{
${ }^{15}$ Crotty (2007, p. 3), a respeito da necessidade de se analisar os resultados detalhados dos grandes bancos, diz: "[...] é quase impossível dar sentido aos oceanos de informação que os conglomerados gigantes fornecem nas suas declarações de resultados e balanços. Estes podem ter centenas de páginas com centenas de notas de rodapé complexas. Somente alguém especializado em contabilidade forense e com muito tempo livre poderia compreender toda essa informação. Assim, o destino dos estudiosos que tentam entender essas empresas e mercados sem um apoio financeiro adequado e, normalmente, sem uma equipe de colegas de trabalho, não é invejável”.

${ }^{16}$ Tal recuo no tempo é complexo pois implica tratar um número bem mais amplo de fusões e aquisições
} 


\section{Gráfico 7: Relação entre}

lucros dos 6 maiores bancos e PIB dos EUA

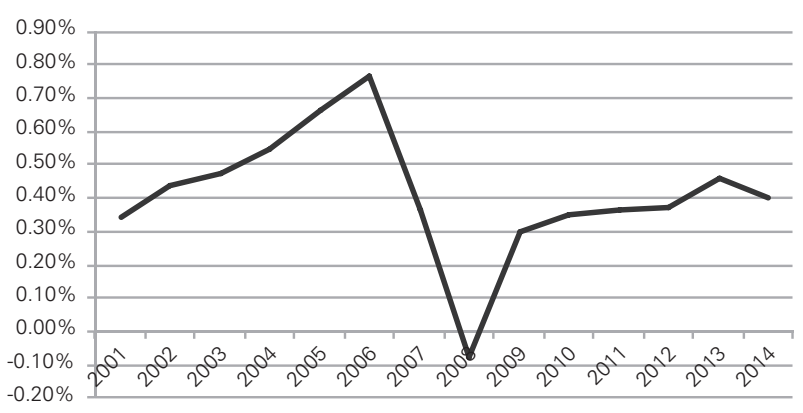

Fonte: Tabelas 6.16 das National Income and Product Accounts disponibilizadas pelo US Bureau of Economic Analysis e

Z.1 Statistical Release do Federal Reserve System.

De qualquer modo, em termos gerais pode-se dizer que a lucratividade dos seis grandes bancos reduziu-se no pós-crise, o que pode ser observado pela queda do retorno sobre ativos e na sua participação sobre os lucros totais na economia. No entanto, isto não indica que a rentabilidade migrou para o buy side: isto parece ser verdadeiro para o período 2009-2012, mas não para 2013 e 2014 e, de qualquer forma, os lucros financeiros como um todo caíram na economia norte-americana. Apesar disso, especialmente se comparado ao PIB, observa-se uma gradual retomada no pós-crise da capacidade geradora de lucros dos bancos.

Por fim, uma ressalva: Crotty (2009) demonstra que as grandes firmas financeiras Norte-americanas não foram durante as últimas duas décadas uma máquina de geração de retornos para seus acionistas e sim para os altos executivos e principais dealmakers destas empresas, que recebiam bônus excepcionais mesmo em períodos de baixo retorno financeiro. Tal observação é relevante pois está é uma dimensão não capturada por este trabalho, pois os lucros já contemplam os pagamentos de bônus e salários. Assim, um caminho para o aprofundamento desta pesquisa seria uma avaliação da variação da remuneração nestas instituições no pós-crise, de forma a identificar o retorno gerado para seus principais executivos no período.

\section{OS LUCROS PÓS-CRISE E A LITERATURA SOBRE A ASCENSÃO DA RENTABILIDADE FINANCEIRA}

Nesta seção, buscamos entender as raízes que levaram à redução, mesmo que relativa, da capacidade dos grandes bancos de gerarem lucros. O caminho natural para tal análise é recorrer à literatura que debateu as causas da ascensão dos lucros

destes bancos, pois as últimas duas décadas foram palco do mais intenso processo de consolidação do sistema bancário dos EUA. 
financeiros e bancários nas últimas décadas e contrastá-la com os dados recentes. A tarefa, no entanto, esbarra em uma ausência surpreendente: como aponta Crotty (2007), apesar da ampla literatura produzida a respeito do processo de financeirização da economia, os estudos que explicam porque os retornos financeiros aumentaram enquanto os demais retornos na economia caíam são escassos e insuficientes. O caráter proprietário das informações de boa parte das instituições financeiras, a complexidade das operações dos maiores bancos e uso intenso de instrumentos que mantêm ativos e passivos fora dos balanços publicados criam dificuldades significativas para tais estudos.

Em que pesem estas dificuldades, alguns paralelos podem ser trabalhados. $\mathrm{O}$ próprio Crotty, no mesmo trabalho em que critica a ausência de análises sobre as origens da lucratividade excepcional, detalha quatro elementos que poderiam explicar os lucros fora da curva do setor financeiro. É esta análise que serve como referência para nossa reflexão sobre a conjuntura mais recente.

O primeiro fator apresentado por Crotty é que a demanda por serviços financeiros cresceu de forma exponencial a partir da década de 1980, acelerando-se na década de 1990. Num contexto de demanda crescente, as pressões por redução de preços seriam menores e, assim, permitiriam maiores margens, além da possibilidade do crescimento dos lucros em termos absolutos pela maior procura pelos serviços financeiros. Esta demanda pelas finanças pode ser avaliada por meio da relação entre ativos financeiros e o PIB. E o que se observa, no Gráfico 8 é que esta proporção seguiu crescendo de forma acelerada após a crise de 2008, mesmo num cenário de baixo crescimento do PIB. Neste sentido, a demanda por serviços financeiros seguiu crescendo e o primeiro fator gerador de lucros excepcionais na visão de Crotty, permanece em ação na atual conjuntura.

Gráfico 8: Ativos financeiros totais em relação ao PIB

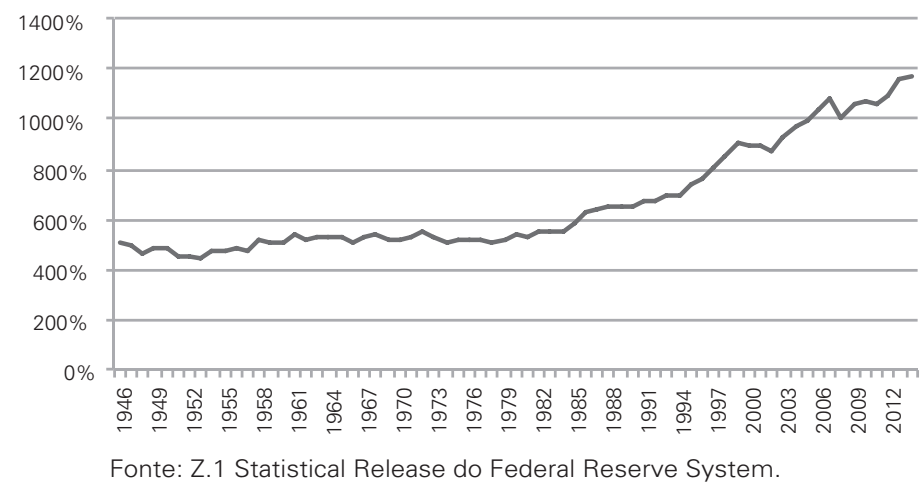

O segundo fator para Crotty é a crescente consolidação do setor, que permitiria o exercício de um poder de oligopólio pelos maiores players. A este respeito, como já discutido neste trabalho, vimos que a conjuntura pós-2008 apresenta níveis ainda maiores de concentração de ativos nos maiores bancos, até mesmo pela der- 
rocada e aquisição de alguns dos concorrentes durante a crise. Desta forma, a segunda razão da excessiva lucratividade do setor financeiro também seguiria válida.

Já a terceira variável indicada por Crotty merece tratamento mais aprofundado. Aqui, o autor traz um ponto levantado por alguns analistas ainda no início da década passada e intensamente debatido após a crise de 2008: a ideia de que os lucros excepcionais do setor financeiro seriam derivados de um risco crescente assumido pelo setor que por muito tempo ficara camuflado em seus balanços patrimoniais.

Neste sentido, Haldane (2010) apresenta três estratégias essenciais pelas quais os bancos alavancaram seus resultados por meio de operações que também aumentavam seus riscos. Uma delas é o chamado tail risk insurance, ou seja, seguros contra eventos raros. ${ }^{17} \mathrm{~A}$ adoção de tais instrumentos sem a reserva apropriada de capital implica a transformação direta de risco em lucros enquanto o evento não acontece, mas provoca perdas significativas em sua ocorrência. Na mesma direção, Raghuram Rajan (2005), economista-chefe do FMI entre 2003 e 2006, apontava que o processo de securitização levava a uma melhor distribuição dos riscos no caso de pequenos choques, mas que o sistema potencialmente havia se tornado muito mais perigoso no caso de um choque significativo, especialmente devido à falta de provisões para o caso de um evento raro. Tais posições estão em linha com a análise de Steinherr (2000), que apontava que os modelos de gerenciamento de risco dos grandes bancos, em geral baseados em séries históricas, eram mal preparados para identificar e lidar com estes eventos raros. Os esforços regulatórios intensificados após 2008 têm tentado diminuir a exposição dos bancos a estes tipos de evento, mas ainda não há informações conclusivas sobre o tema.

A segunda e terceira estratégias apontadas por Haldane (2010) estão ligadas diretamente à alavancagem ou às operações que levam a manobras contábeis para permitir uma alavancagem maior. A questão da alavancagem é tão significativa que levou Haldane a indicar, olhando para os bancos britânicos, que "virtualmente todo o crescimento no retorno sobre capital no último século [...] parece ser resultado do aumento da alavancagem".

Assim, é importante avaliar como evoluiu a alavancagem dos grandes bancos desde a crise de 2008, o que é feito no Gráfico 9, em que a alavancagem é apresentada em paralelo ao retorno sobre capital dos bancos, sendo a alavancagem calculada de forma bruta, dividindo os ativos totais pelo capital próprio. Pode-se então notar o significativo alinhamento destas variáveis nos últimos 15 anos, de forma que é bastante razoável supor que a redução da alavancagem foi importante fator na queda da lucratividade dos bancos nos anos pós-crise. Ressalta-se, além disso,

\footnotetext{
${ }^{17}$ Os Credit Default Swaps (CDSs), que estiveram no centro da crise, são um destes produtos. CECILIO (2012, p. 100): “Um CDS funciona como um seguro contra o calote dos títulos. A grande diferença entre o CDS e um seguro comum é que com um CDS se pode segurar bens que o investidor não possui. Assim, enquanto uma casa pode ser segurada uma única vez contra incêndios, por meio de um CDS qualquer pessoa pode criar um seguro contra o incêndio daquela casa especificamente. Como se pode imaginar, no caso de um incêndio de verdade, o prejuízo não está limitado ao valor da casa: ele é multiplicado pela quantidade de diferentes pessoas que buscaram aquele seguro".
} 
que boa parte da nova onda regulatória após a crise teve como objetivo justamente aumentar as exigências de capital, implicando assim uma redução dos níveis de alavancagem dos grandes bancos, o que de fato foi alcançado.

Gráfico 9: 6 maiores bancos: Retorno sobre capital e Alavancagem

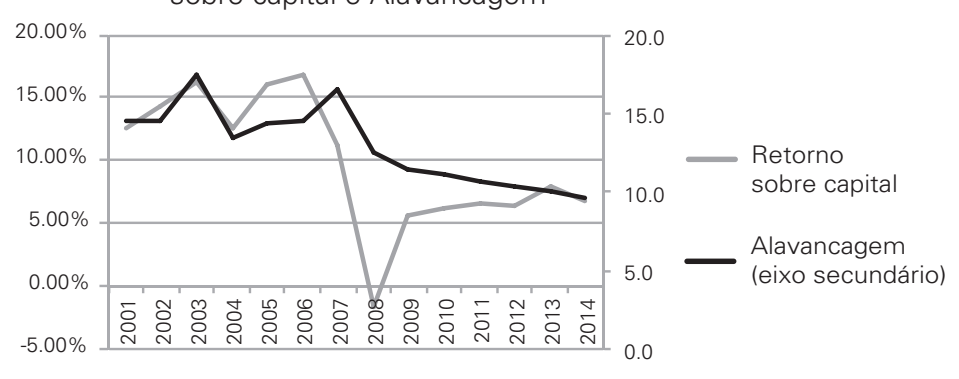

Fonte: Balanços anuais dos bancos.

Alavancagem calculada de forma bruta, dividindo os ativos pelo capital próprio.

Ainda a respeito desta relação entre risco e retorno, duas outras observações são relevantes. A primeira diz respeito ao proprietary trading, ou seja, negociações feitas em mercado pelos bancos com capital próprio. Embora este não seja um elemento diretamente apontado por Crotty e Haldane, é evidente que num mercado em ascensão os lucros gerados pelo proprietary trading foram significativos, do mesmo modo que as perdas quando houve um colapso do mercado também o foram. Até por isso, parte da regulação pós-2008 buscava restringir a autonomia dos bancos para atuar desta forma. A mensuração do proprietary trading não é simples, mas recente relatório do BIS - Bank for International Settlements - (Committee On The Global Financial System, 2015) aponta que é provável que tenha havido alguma redução em seu volume, porém com mais força na zona do euro do que nos EUA, impactando assim os lucros, mesmo que de forma tímida. Os efeitos da regulação sobre o proprietary trading para os lucros dos bancos Norte-americanos precisaria ser analisada após 2015, quando a Volcker Rule, o dispositivo regulatório criado pela Dodd-Frank a respeito do tema, entrou de fato em efeito, embora sua revisão já esteja em debate pelos reguladores.

A segunda observação diz respeito aos juros. Como já discutido, o pós-crise foi um período de taxas próximas de zero, constituindo um efeito redutor dos lucros, embora não pareça ter sido a razão fundamental para a redução significativa pois os spreads nos primeiros anos pós-crise ainda seguiu superior ao dos últimos anos antes da bolha. É possível que a principal razão para este descasamento seja o apresentado por Stiroh (2004): durante as últimas décadas os bancos migraram parte crescente de seu faturamento para receitas não ligadas a juros e sim a fees originados na criação de instrumentos financeiros, apoio a fusões e aquisições, estruturação de empréstimos e outras receitas não ligadas a empréstimos diretos. Tal fato é ainda mais relevante para os bancos com forte atuação como banco de investimento, como os seis bancos usados nesta análise. Embora por muito tempo 
boa parte dos economistas viu nesta migração um movimento de redução de riscos em função da diversificação das receitas, Stiroth demonstra que em função de seu caráter volátil a dependência dos bancos às receitas não ligadas a juros aumentava e não diminuía o seu risco.

Por fim, a quarta variável sugerida por Crotty para explicar a lucratividade dos bancos derivaria de sua capacidade inovadora. Assim como as empresas que lançam novas tecnologias desfrutam de lucros excepcionais enquanto seus concorrentes não copiam os novos produtos, os bancos por meio de seus derivativos OTC (over the counter) desfrutariam da mesma situação, numa posição ainda mais privilegiada, pois estes derivativos não são precificados de forma pública. Neste caso, estes produtos inovadores geram margens excepcionais, pois os investidores não podem encontrar tais produtos em concorrentes, além da assimetria de informação existente entre os originadores do produto e seus compradores. ${ }^{18}$ Como se pode observar no Gráfico 10, o montante total de derivativos de fato explodiu no decorrer da última década e ainda que em relação ao PIB eles tenham recuado em relação ao pico de 2010, continuam num patamar elevado, tornando reduzido seu potencial impacto sobre a perda de rentabilidade dos bancos. Ainda a respeito dos derivativos, é válido destacar que os seis grandes bancos Norte-americanos controlam mais de 95\% deste mercado e embora haja uma tentativa dos reguladores de reduzir o mercado de derivativos negociados OTC em favor daqueles negociados em bolsas de liquidação e de compensação, o índice de derivativos OTC em relação ao total reduziu-se em apenas $1 \%$ desde 2008 , estando ainda no altíssimo patamar de $95 \%$.

Gráfico 10: Evolução do valor dos derivativos e PIB (em trilhões de dólares)

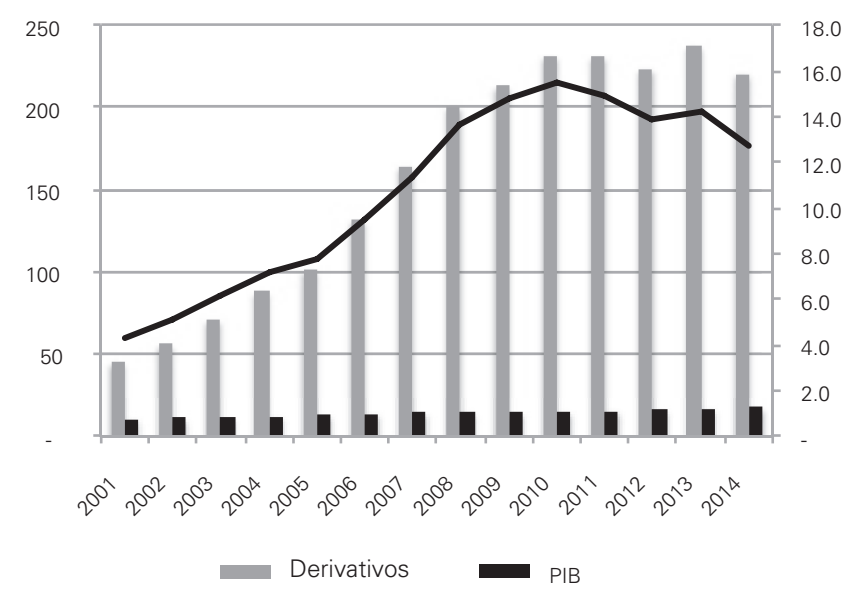

Fonte: Quarterly Report on Bank Derivatives Activities publicado pelo Office of the Controller of the Currency, ligado ao U.S. Department of the Treasury e disponível em http://www.occ.gov/topics/capital-markets/financial-markets/

\footnotetext{
${ }^{18}$ Para exemplos desta assimetria de informações, ver Cecilio (2012 p. 98).
} 
trading/derivatives/derivatives-quarterly-report.htmlQuarterly Report on Bank Derivatives Activities publicado pelo Office of the Controller of the Currency, ligado ao U.S. Department of the Treasury e disponível em http://www.occ. gov/topics/capital-markets/financial-markets/trading/derivatives/derivativesquarterly-report.html

Desta forma, considerados os quatro fatores de lucratividade excepcional apontados por Crotty, o que se apresenta como variável capaz de explicar a relativa queda de rentabilidade dos bancos é a redução em sua alavancagem, uma das demandas regulatórias pós-2008. A expansão da demanda por produtos financeiros, a crescente concentração do setor e a inovação em derivativos OTC seguem atuando como forças alimentadoras dos lucros. As taxas de juros próximas de zero, ainda que possam ter cumprido algum papel na redução da lucratividade, tampouco são capazes de explicar de forma determinante a queda dos lucros.

\section{CONCLUSÃO}

Em 2010, Taibbi publicou um artigo a respeito do papel da Goldman Sachs na construção histórica que levou à crise de 2008 com uma imagem impactante que por um longo tempo reverberou na imprensa norte-americana: a Goldman Sachs seria uma "imensa lula-vampiro agarrada no rosto da humanidade, incansavelmente enfiando seu funil de sangue em qualquer coisa que cheire dinheiro". Em que pese a força da imagem, a investigação deste trabalho indica que a lula, entendida como os seis grandes bancos Norte-americanos, afrouxou seu aperto. $\mathrm{O}$ retorno sobre capital dos seis maiores bancos caiu significativamente e hoje seus lucros representam $40 \%$ menos em relação aos lucros totais da economia do que no começo da década anterior. O maior responsável por esta queda possivelmente foi a redução de sua alavancagem, uma medida originada nas mudanças regulatórias pós-crise.

No entanto, tal redução não indica necessariamente uma ascensão do buy side: os lucros financeiros como um todo caíram e se o período 2009-2012 dá sinais desta escalada do buy side, tal movimento não se sustentou em 2013 e 2014.

Por fim, é importante notar que a queda dos lucros dos bancos parece menor ao ser contrastada a outros indicadores: ao comparar os lucros com o PIB, novamente se observa a lula-vampiro retomando seu aperto sobre a economia real. Embora ainda não atinja os níveis inacreditáveis do meio da década passada, a impressão é de que os seis maiores bancos seguem com uma capacidade de geração de lucros mais similar a um patamar baixo do novo padrão construído a partir do final da década de 1980 do que um retorno aos padrões de lucratividade reduzida do pós-Guerra. Tal fato seria também resultado da manutenção de três variáveis que ajudaram a explicar a ascensão da rentabilidade financeira na década de 1990: a ampla demanda por produtos financeiros, a crescente concentração do setor e o significativo volume de produtos inovadores que seguem sem mercados públicos.

Além disso, este trabalho abre alguns interessantes caminhos para pesquisas 
futuras. O primeiro seria avaliar o comportamento de salários e bônus nos grandes bancos no pós-crise, de forma a identificar se continuaram a gerar retorno excepcionais para seus altos executivos. Também para o período pós-crise, seria importante avaliar o lucro financeiro das empresas não financeiras, um componente essencial da narrativa sobre a financeirização construída nas décadas de 1990 e 2000. O terceiro caminho de pesquisa seria ampliar o horizonte de análise da rentabilidade dos seis bancos para as décadas de 1980 e 1990, criando um cenário comparativo mais rico para se interpretar os dados recentes. O quarto seria aprofundar na análise da conjuntura de 2013 e 2014, quando há um descolamento entre resultados dos seis grandes bancos e do setor financeiro como um todo, como forma de avaliar a eventual migração de rentabilidade do buy side para o sell side. E, por fim, expandir a análise para incorporar dados a respeito do proprietary trading, uma das possíveis fontes excepcionais de rentabilidade para estes bancos, pode ajudar a oferecer um quadro mais completo a respeito das variações na lucratividade nestes últimos anos.

\section{REFERÊNCIAS BIBLIOGRÁFICAS}

ADRIAN, Tobias e ASHCRAFT, Ashcraft. (2012) Shadow Banking: A Review of the Literature. Federal Reserve Bank of New York Staff Reports, no. 580, October. Disponível em <https://www. newyorkfed.org/medialibrary/media/research/staff_reports/sr580.pdf>. Acesso em 22 de dezembro de 2015

BORIO, Claudio, GAMBACORTA, Leonardo e HOFMANN, Boris. (2015) "The influence of monetary policy on bank profitability". BIS Working Papers No 514. Disponível em <http://www.bis. org/publ/work514.pdf>. Acesso em 18 de Julho de 2017.

CECILIO, Marco B. (2012) Fernand Braudel e a Acumulação Acelerada de Riquezas: Economia de Mercado e Capitalismo Como Opostos? Tese de Mestrado, Universidade Federal do Rio de Janeiro. Disponível em <http://www.ie.ufrj.br/images/pos-graducao/pepi/dissertacoes/CECILIO_ Marco_-_FERNAND_BRAUDEL_NO_MUNDO.pdf> Acesso em: 10/02/2013

CINTRA, Marcos A. M. e CAGNIN, Rafael F.(2007) "Evolução da estrutura e da dinâmica das finanças norte-americanas”. Econômica, Vol. 9, n. 2, dezembro, pp. 296-338.

CINTRA, Marcos A. M.; CAGNIN, Rafael F e FARHI, Maryse.(2008) "A crise financeira e o global shadow banking system". Novos estudos - CEBRAP, n.82, pp. 35-55.

CLINTON, Hillary. (2015) Hillary Clinton: How I'd Rein In Wall Street. New York Times, New York, 7/Setembro/2015. Disponível em <http://www.nytimes.com/2015/12/07/opinion/hillary-clinton-how-id-rein-in-wall-street.html?_r=0>. Acesso em 18 de dezembro de 2015

COMMITTEE ON THE GLOBAL FINANCIAL SYSTEM.(2015) Market-making and proprietary trading: industry trends, drivers and policy implications.CGFS Papers, Bank for International Settlements, No 52. Disponível em <http://www.bis.org/publ/cgfs52.pdf>. Acesso em 07 de Janeiro de 2015.

COUNCIL OF ECONOMIC ADVISERS (2017). Economic Report of the President. Janeiro. Disponível em < http://www.presidency.ucsb.edu/economic_reports/2017.pdf>. Acesso em 19 de Julho de 2017.

CROTTY, James. (2007) "If Financial Market Competition is so Intense, Why are Financial Firm Profits. Disponível em <http://people.umass.edu/crotty/WP134.pdf>. Acesso em 6 de Junho de 2012.

CROTTY, James (2009). “The Bonus-Driven “Rainmaker” Financial Firm: How These Firms Enrich Top Employees, Destroy Shareholder Value and Create Systemic Financial Instability”. Economics Department Working Paper Series. Paper 2. 
DI LUCIDO, Katherine, KOVNER, Anna e ZELLER, Samantha. (2017) “Low Interest Rates and Bank Profits". Liberty Street Economics, 21/Julho/2017. Disponível em <http://libertystreeteconomics. newyorkfed.org/2017/06/low-interest-rates-and-bank-profits.html>. Acesso em 18 de Julho de 2017.

EPSTEIN, Gerald. (2015) “Financialization: There's Something Happening Here”. Political Economy Research Institute Working Paper Series Number 394. Disponível em <http://www.peri.umass. edu/fileadmin/pdf/working_papers/working_papers_351-400/WP394.pdf >. Acesso em 20 de janeiro de 2016.

HALDANE, Andrew. (2010) “The Contribution of the Financial Sector: Miracule or Mirage?”. Discurso realizado na Conferência Future of Financie, Londres. Disponível em <https://www.bankofengland.co.uk/publications/speeches/2010/speech442.pdf>. Acesso em 08 de Janeiro de 2016.

HELLEINER, E. (2010) "A Bretton Woods moment? the 2007-2008 crisis and the future of global finance”. International Affairs, vol. 86, n.3, pp. 619-636.

HODGE, Andrew W. (2011) "Comparing NIPA Profits With S\&P 500 Profits". Survey of Current Business, Volume 91 Number 3. Disponível em <https://www.bea.gov/scb/pdf/2011/03\%20March/0311_profits.pdf $>$. Acesso em 20 de janeiro de 2016.

KRIPPNER, Greta R. (2011) Capitalizing on Crisis: The Political Origins of the Rise of Finance. Cambridge, Harvard University Press.

NÖLKE, Andreas; HEIRES, Marcel \& BILLING, Hans-Jürgen Bieling (2013). “Editorial: The Politics of Financialization." Competition and change, Vol. 17 No. 3, August 2013, 209-18

MARSH Alastair \& NATARAJAN Sridhar (2016). "The Rise of the Buy Side”. Bloomberg Markets. 15/8/2016. Disponível em < https://www.bloomberg.com/news/features/2016-08-15/the-rise-of-the-buy-side>. Acesso em 18 de julho de 2017

RAJAN, R. (2005) “Has Financial Development Made the World Riskier?” NBER Working Paper No. W11728.

ROBERT, Daniel. (2015) “The Volcker Rule takes effect today after years of delays”. Fortune. 22/7/2015. Disponível em <http://fortune.com/2015/07/22/volcker-rule/>. Acesso em 21 de dezembro de 2015.

SERNOVITZ, Gary. (2015) “What Hillary Clinton Gets (and Bernie Sanders Doesn't) About Wall Street”. The New Yorker Magazine, 10/12/2015. Disponível em <http://www.newyorker.com/ business/currency/hillary-clinton-gets-bernie-sanders-doesnt-wall-street>. Acesso em 18 de dezembro de 2015

SMITH, Geoffrey. (2015) "GE is taking the axe to its finance arm in a landmark strategy shift". Fortune. 10/4/2015. Disponível em <http://fortune.com/2015/04/10/ge-taxes-the-ax-to-its-finance-arm-in-landmark-strategy-shift/>. Acesso em 28 de dezembro de 2015.

STEINHERR, A. (2000) Derivatives: The Wild Beast of Finance. New York, Wiley.

STIROH, K. (2004) "Diversification in Banking: Is noninterest income the answer?" Journal of Money, Credit and Banking, 36 (5), October, 853-882.

TAIBBI Matt. (2010) “The Great American Bubble Machine”. Rolling Stone, 5/4/2010. Disponível em $<$ http://www.rollingstone.com/politics/news/the-great-american-bubble- machine-20100405>. Acesso em: 30/04/2012 